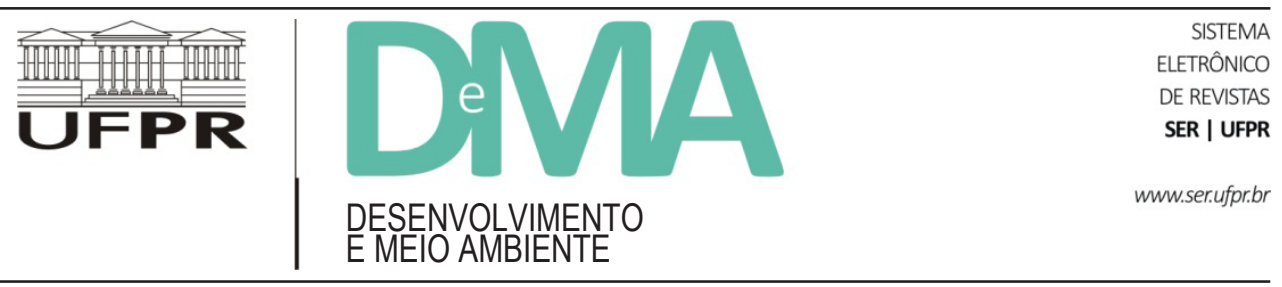

\title{
Mar de quem? Crítica, sentimentos de (in)justiça e justificações em um conflito ambiental: empreendimentos portuários vs. pesca artesanal no litoral sul do Espírito Santo, Brasil
}

\section{Whose sea? Criticism, Feelings of (In)Justice and Justifications in an Environmental Conflict: Port Developments vs Artisanal Fishing in the South Coast of Espírito Santo, Brazil}

\author{
Ana Cláudia Hebling MEIRA ${ }^{1 *}$, Jalcione ALMEIDA ${ }^{2}$ \\ ${ }^{1}$ Centro de Ciências Agrárias e Engenharias (CCAE), Universidade Federal do Espírito Santo (UFES), Alegre, ES, Brasil. \\ ${ }^{2}$ Departamento de Sociologia (IFCH), Universidade Federal do Rio Grande do Sul (UFRGS), Porto Alegre, RS, Brasil. \\ *E-mail de contato: anameira2002@gmail.com
}

Artigo recebido em 3 de maio de 2016, versão final aceita em 14 de setembro de 2016.

RESUMO: Disputas em torno de três grandes projetos de desenvolvimento em curso no litoral sul do Espírito Santo, Brasil, e três comunidades de pescadores artesanais são o tema de pesquisa de que trata este artigo. Baseado em trabalho ainda em andamento, propõe-se o conceito de conflito ambiental para analisar essas disputas e suas decorrências, interpretando-o como categoria híbrida de sociedade e natureza e buscando reforçar sua carga cosmopolítica. A partir dessa perspectiva, sugere-se um quadro analítico que considera a crítica como manifestações enraizadas no contexto social e que se baseiam em sentimentos de justiça/injustiça. Após análise preliminar de informações obtidas em pesquisa de campo, verifica-se que os sentimentos de justiça/injustiça que estão na base da crítica social se constroem a partir da (e na) relação sociedade-natureza, configurando uma diversidade de concepções de justiça que não pode ser reduzida às concepções de justiça como bem comum, ou como uma noção de justiça que se impõe ao conjunto da sociedade como forma capaz de solucionar conflitos. Ao contrário, a copresença problemática de práticas permite sugerir a noção de cosmojustiça para expressar a diversidade irredutível de sentimentos de justiça/injustiça na realidade estudada.

Palavras-chave: crítica; conflito ambiental; injustiça; cosmopolítica.

ABSTRACT: Disputes around three large development projects in the south coast of Espirito Santo, Brazil, and three communities of artisanal fishermen are the object of research in this article. Based on work in progress, we proposed the concept of environmental conflict to analyze these disputes and its consequences, interpreted as a hybrid category of society and nature, and seeking to strengthen its cosmopolitics charge. From this perspective, it is 
suggested an analytical framework that considers the criticism as manifestations rooted in the social context and based on feelings of justice/injustice. After analyzing information obtained in field research, it appears that the feelings of justice/injustice that are the basis of social criticism are built from the society/nature relationships, setting up a diversity of conceptions of justice that cannot be reduced to the concept of justice as a common good, or as a sense of justice that encompasses the whole society as a way to resolve conflicts. Instead, the problematic co-presence of the practices allows the suggestion of the notion of cosmojustice to express the irreducible diversity of feelings of justice/injustice.

Keywords: criticism; environmental conflicts; justice/injustice; cosmopolitics.

\section{Introdução}

O presente artigo se origina do esforço de pesquisa que tem como objeto as disputas em torno das ações de desenvolvimento que visam à implantação de grandes projetos de investimento em infraestrutura portuária no litoral sul do Espírito Santo, Brasil. Essa reflexão se insere no quadro de esforços acadêmicos recentes empreendidos pelas ciências sociais para aprofundar estudos no campo da "sociologia da questão ambiental".

Historicamente, a sociologia primou pela clara separação entre o natural e o social na definição de seus objetos de estudos. Entretanto, com a emergência, na década de 1970, do ambiente como questão social, fizeram-se necessários uma reflexão teórico-epistemológica e o desenvolvimento de metodologias capazes de orientar problematizações no âmbito da temática ambiental.

Não há espaço neste artigo para recuperar todo o debate em torno dessa temática. ${ }^{1}$ Por essa razão, o foco será na forma como este ocorre no Brasil e, mais especificamente, em trabalhos realizados no Grupo de Pesquisa em Tecnologia, Meio Ambiente e Sociedade (Temas - www.ufrgs.br/temas). O que se propõe aqui é tratar a relação sociedade-natureza a partir de um embasamento teórico específico, com o propósito de sugerir um quadro analítico que considere a crítica e seus determinantes (sociais e naturais) como formas contestadoras enraizadas no contexto das sociedades. ${ }^{2}$ Nesse quadro, agentes sociais são considerados capazes de organizar seus interesses e se colocar a serviço de uma atividade crítica, levando em consideração diferentes cosmovisões (como produto dos agenciamentos híbridos de sociedade e natureza) que informam a constituição de sentimentos de justiça/injustiça.

Esta pesquisa foi realizada em um contexto empírico caracterizado pela adoção de estratégias de modernização/industrialização em um território com presença de comunidades locais, mais especificamente pescadores artesanais, pequenos agricultores, remanescentes de quilombos e descendentes de indígenas.

Apesar de se tratar de um estudo ainda em andamento, o estágio da pesquisa já permite algumas reflexões, principalmente no que se refere à enunciação (e algumas de suas consequências) dos sentimentos de justiça/injustiça que estão na base do conflito em tela.

Este artigo está dividido em quatro seções, além desta introdução: a primeira faz uma des-

\footnotetext{
1 Sobre esse debate, ver síntese em Almeida \& Premebida (2014), Fleury et al. (2014) e Fleury (2013).

2 Como se verá mais adiante, o que se propõe é o delineamento de um corpus teórico no quadro de uma sociologia da questão ambiental nascente, tendo como ponto de partida a abordagem da sociologia crítica pragmática (particularmente de Boltanski e colaboradores) na combinação com uma abordagem pós-construcionista.
} 
crição do campo empírico; a segunda se destina a apresentar o desenvolvimento do presente estudo até o momento, sua questão principal, as reflexões teóricas e hipótese; a terceira coloca em diálogo, em perspectiva analítica, as concepções teóricas e as informações produzidas na pesquisa de campo; e a quarta apresenta algumas reflexões à guisa de conclusões.

\section{O contexto do (não) desenvolvimento, agentes sociais e as críticas}

O litoral sul do estado do Espírito Santo, desde o período colonial, foi "construído" como o lugar do "não desenvolvimento". Primeiramente, em decorrência do estabelecimento de uma "barreira verde" para impedir o contrabando de ouro e pedras preciosas de Minas Gerais, as povoações foram limitadas à faixa litorânea, sendo proibida a entrada para o sertão, que no discurso da época era o local da "ausência de civilização", o local do indígena. A maioria das fazendas do litoral era de propriedade dos jesuítas e nelas se produziam farinha e hortaliças e se criava gado. A mão de obra era escrava e indígena. Com a expulsão dos jesuítas pela coroa portuguesa, houve o "esvaziamento" populacional dessa região e uma consequente perda de importância econômica. A atividade agrícola ficou restrita ao autoconsumo e diminuíram consideravelmente as atividades comerciais. A forte herança indígena da região contribuiu para a "construção" do discurso do "vazio" e do "atraso".

Na segunda metade do século XIX, com a vinda de imigrantes europeus, em sua maioria italianos, e em função da dinâmica da economia internacional, instaurou-se o cultivo do café e promoveu-se a colonização do sertão por meio da implantação de vários núcleos coloniais. $\mathrm{Na}$ ocasião, utilizou-se a noção de "vazio demográfico" para justificar a ocupação, desconsiderando-se a existência de indígenas, escravos fugidos, posseiros, entre outros.

Atribui-se o atraso econômico do Espírito Santo em relação ao Rio de Janeiro, a São Paulo e a Minas Gerais à dificuldade na ocupação do território capixaba, circunscrito ao litoral (até meados do século XIX). Outro fator que contribui para a interpretação do Espírito Santo como atrasado é o fato de que, diferentemente de outras regiões do país, o modelo da plantation escravista não se disseminou por todo o território, estando concentrado apenas em algumas regiões, tendo como determinantes as particularidades da geografia local (montanhas e muitas áreas alagadas), as dificuldades de ocupação de determinadas áreas do território por conta da presença indígena e a proibição da abertura de estradas em direção às áreas de mineração, o que provocou um isolamento da província e impediu o crescimento de sua população (Martins, 2014, p. 26).

Vários estudos apontam para o fato de que, por ser baseada na pequena propriedade familiar, a cafeicultura, principal atividade econômica no século XIX, não possibilitou o desenvolvimento de circuitos de valorização do capital que permitissem investimentos em outras áreas além da própria cafeicultura. Mas, paradoxalmente, para fortalecer as exportações do café, na década de 1920, foram feitos investimentos em infraestrutura que seriam importantes no momento de transição da economia cafeeira para a economia urbano-industrial. Trata-se, mais especificamente, do desenvolvimento das atividades portuárias e da construção de estradas de ferro.

Com a crise da produção cafeeira, a política nacional de erradicação dos cafezais, na década de 1950, e a criação da Sudene, houve um movimento reivindicatório para incluir o Espírito Santo na po- 
lítica regional brasileira (principalmente em função dos baixos indicadores socioeconômicos) e a defesa da industrialização como forma de alavancagem do desenvolvimento.

Durante os anos 1960 e 1970, o processo de industrialização ocorreu de maneira centralizada na região metropolitana de Vitória, em decorrência do fato de que ali se concentrava a maior parte da infraestrutura herdada do período em que predominavam as exportações de café. Com a existência do porto e das estradas de ferro, o Espírito Santo passou a ser exportador de produtos semi-industrializados.

Assim, o litoral sul do Espírito Santo, que historicamente foi construído pelo discurso hegemônico como "vazio" e "atrasado", permaneceu pouco ocupado e "não desenvolvido", com rara exceção feita ao município de Anchieta, que, na década de 1970, no bojo dos grandes investimentos para o desenvolvimento (no que se poderia chamar de primeira fase da industrialização capixaba), recebeu investimentos da Samarco Mineração S.A., com a instalação de uma usina de pelotização de minério de ferro e de um terminal portuário. Essa atividade veio a agregar outras empresas, compondo um setor industrial com aproximadamente 50 empresas responsáveis por cerca de $79 \%$ da composição do PIB do município (ABE, 2006).

No começo dos anos 2000, iniciou-se uma nova fase de impulso desenvolvimentista, que produziu, em 2006, um de seus dispositivos mais emblemáticos: o "Espírito Santo 2025: plano de desenvolvimento" (Secretaria de Estado de Economia e Planejamento do Espírito Santo, 2006). Trata-se de documento elaborado pela Secretaria de Estado de Economia e Planejamento, em conjunto com o
Movimento Espírito Santo em Ação ${ }^{3}$, e patrocinado pela Petrobras. Com o objetivo de estabelecer um plano de metas para o Espírito Santo até o ano de 2025 , esse documento deixa clara a perspectiva de que desenvolvimento significa industrialização-urbanização e, além disso, que se deve "descentralizá-lo", levando-o às regiões "menos desenvolvidas", "vazias" e "atrasadas". Uma dessas regiões é a microrregião litoral sul. Por essa razão, a partir do início dos anos 2000, uma série de grandes "projetos de desenvolvimento" vem sendo proposta e colocada em prática, por meio de investimentos públicos e privados. Esses grandes projetos, no entanto, resultaram na ameaça à sobrevivência de comunidades locais e em conflitos.

Mas quais são as comunidades dessa região que acabam por se tornar invisibilizadas pelo discurso do "vazio", do "atraso" e do(a) "não (falta de) desenvolvimento"? Principalmente, são aquelas constituídas por pequenos agricultores de base familiar, descendentes de indígenas, pescadores artesanais, profissionais das diversas áreas do turismo, homens e mulheres, crianças, jovens, adultos e idosos, grupos que professam diversas crenças religiosas e se relacionam com o ambiente de maneira também diversa, tanto do ponto de vista material como simbólico.

Apresentam-se a seguir alguns dados estatísticos apenas para melhor ilustrar e apresentar um quadro a quem não conhece a região. Entretanto, esses dados não serão tomados como absolutos, pois se sabe que não falam por si e que uma população é sempre dinâmica e plural. ${ }^{4}$

As Tabelas 1 e 2 mostram que o litoral sul do Espírito Santo não apenas não é um "vazio" como,

\footnotetext{
3 Movimento organizado por empresários de diversos setores produtivos.

4 Para se manter a coerência epistemológica, não serão utilizadas, para fins analíticos, totalidades sociais, quaisquer que sejam elas, como "população", "sociedade" ou outras.
} 
mais do que isso, é ocupado por um conjunto de pessoas que descendem de grupos familiares que estão nesse local há mais de um século. Evidenciam também alguns elementos que contribuem para que essa região seja construída como "atrasada" e "pouco desenvolvida", como, por exemplo, o fato de que, em alguns municípios, a população rural é maior que a população urbana.

A Tabela 2 demonstra a diversidade étnico-racial da microrregião litoral sul, com destaque para a presença, em quase todos os municípios, de grupos que se identificam como indígenas e uma importante parcela de indivíduos que se declaram de cor parda, o que sugere uma miscigenação entre brancos e indígenas.

Com a finalidade de evidenciar ainda mais as características do ordenamento social em questão, destaca-se a presença de uma comunidade quilombola autocertificada, de aproximadamente 7.800 pescadores artesanais e de uma área indígena em processo de reconhecimento pela Funai. ${ }^{5}$

Ao se analisar o número de estabelecimentos agropecuários por condição em relação à agricultura familiar, ainda na microrregião litoral sul do Espírito Santo, verifica-se que os números relativos ao percentual dos estabelecimentos agropecuários

TABELA 1 - População residente na microrregião litoral sul, Espírito Santo, por situação do domicílio (2010)

\begin{tabular}{lccccc}
\hline \multicolumn{1}{c}{ Município } & Total & Urbano & Rural & \% Urbano & \% Rural \\
\hline Alfredo Chaves & 13.955 & 6.545 & 7.410 & 46,90 & 53,10 \\
Anchieta & 23.902 & 18.161 & 5.741 & 75,98 & 24,02 \\
Iconha & 12.523 & 7.277 & 5.246 & 58,11 & 41,89 \\
Itapemirim & 30.988 & 19.330 & 11.658 & 62,38 & 37,62 \\
Marataízes & 34.140 & 27.614 & 6.526 & 80,88 & 19,12 \\
Piúma & 18.123 & 17.449 & 674 & 96,28 & 3,72 \\
Pres. Kennedy & 10.314 & 3.440 & 6.874 & 33,35 & 66,65 \\
Rio Novo do Sul & 11.325 & 5.946 & 5.379 & 52,50 & 47,50 \\
Total & $\mathbf{1 5 5 . 2 7 0}$ & $\mathbf{1 0 5 . 7 6 2}$ & $\mathbf{4 9 . 5 0 8}$ & $\mathbf{6 8 , 1 1}$ & $\mathbf{3 1 , 8 9}$ \\
\hline
\end{tabular}

FONTE: IBGE, Censo Demográfico (2010).

TABELA 2 - População residente na microrregião litoral sul, Espírito Santo, por cor ou raça (2010)

\begin{tabular}{lcccccc}
\hline \multicolumn{1}{c}{ Município } & Total & Branca & Preta & Amarela & Parda & Indígena \\
\hline Alfredo Chaves & 13.955 & 9.417 & 484 & 41 & 3.993 & 20 \\
Anchieta & 23.902 & 10.110 & 1.608 & 168 & 11.896 & 120 \\
Iconha & 12.523 & 8.619 & 267 & 19 & 3.612 & 6 \\
Itapemirim & 30.988 & 15.139 & 1.829 & 181 & 13.813 & 26 \\
Marataízes & 34.140 & 20.363 & 1.403 & 152 & 12.197 & 25 \\
Piúma & 18.123 & 9.516 & 924 & 91 & 7.559 & 33 \\
Pres. Kennedy & 10.314 & 3.774 & 1.040 & 70 & 5.425 & 5 \\
Rio Novo do Sul & 11.325 & 6.354 & 311 & 6 & 4.654 & - \\
Total & $\mathbf{1 5 5 . 2 7 0}$ & $\mathbf{8 3 . 2 9 2}$ & $\mathbf{7 . 8 6 6}$ & $\mathbf{7 2 8}$ & $\mathbf{6 3 . 1 4 9}$ & $\mathbf{2 3 5}$ \\
\hline
\end{tabular}

FONTE: IBGE, Censo Demográfico (2010).

5 Conforme dados do Sistema de Informações Territoriais do Ministério do Desenvolvimento Agrário (ano de referência: 2010). 
de base familiar, demonstrados na Tabela 3, abaixo, além de confirmarem que o processo de colonização e ocupação territorial no litoral sul capixaba se deu por intermédio das pequenas propriedades, contribuem sobremaneira para a construção dessa região como "atrasada".

Baseado nessa visão de "atraso", em 2003, o então governador criou a Secretaria de Estado de Desenvolvimento (Sedes) com o objetivo de propor e implantar projetos que direcionassem o crescimento capixaba e a geração de novas oportunidades na economia. Essa secretaria deveria, então, atuar como "interlocutora entre os setores produtivos, visando à ampliação da competitividade, desenvolvimento dos setores, aceleração da indústria e de sua cadeia produtiva, fomentando a criação e manutenção de emprego e renda e a evolução da capacitação profissional" (Secretaria de Estado de Desenvolvimento, 2016).

A partir de 2006, o governo do estado passa então a adotar a seguinte definição de desenvolvimento:

Desenvolvimento. Este vocábulo exprime os sonhos e as lutas de muitas gerações, no Brasil e em muitas outras regiões do mundo. Em muitos aspectos a sociedade brasileira mudou e avançou nas últimas décadas. Mudou também a forma de adjetivar o estágio de desenvolvimento brasileiro: subdesenvolvido, em desenvolvimento e depois emergente. Mas a distância que separa os indicadores sociais e o dinamismo econômico no Brasil dos vigentes nos países desenvolvidos ainda nos remete a desafios que parecem pertencer ao "país do futuro", geração após geração. Talvez porque um futuro substancialmente melhor parece sempre distante e improvável, quando não somos bem-sucedidos nas batalhas do presente ou quando não construímos uma visão convergente sobre qual caminho trilhar (Secretaria de Estado de Economia e Planejamento, 2006, p. 10).

Embora expresse claramente a crença de que as ações de desenvolvimento devem buscar a redução da distância entre indicadores sociais e econômicos, a maior quantidade de investimentos do estado para a promoção do desenvolvimento está direcionada a incentivar instalações de grandes projetos, com destaque para as políticas de atração de investimentos industriais, principalmente nas áreas de produção de energia, siderurgia, metalurgia e infraestrutura portuária.

Na última década, têm-se vários investimentos previstos e/ou implantados no litoral sul que passaram (ou ainda passam) por vários questionamentos

TABELA 3 - Número de estabelecimentos agropecuários, por condição em relação à agricultura familiar, na microrregião litoral sul do Espírito Santo (2006)

\begin{tabular}{lccccc}
\hline \multicolumn{1}{c}{ Município } & Total & Não familiar & $\begin{array}{c}\text { Agricultura } \\
\text { familiar }\end{array}$ & \% Não familiar & $\begin{array}{c}\text { \% Agricultura } \\
\text { familiar }\end{array}$ \\
\hline Alfredo Chaves & 1.170 & 168 & 1.002 & 14,36 & 85,64 \\
Anchieta & 494 & 127 & 367 & 25,71 & 74,29 \\
Iconha & 1.123 & 99 & 1.024 & 8,82 & 91,18 \\
Itapemirim & 792 & 120 & 672 & 15,15 & 84,85 \\
Marataízes & 1.382 & 147 & 1.235 & 10,64 & 89,36 \\
Piúma & 179 & 54 & 125 & 30,17 & 69,83 \\
Pres. Kennedy & 718 & 131 & 587 & 18,25 & 81,75 \\
Rio Novo do Sul & 644 & 68 & 576 & 10,56 & 89,44 \\
Total & $\mathbf{6 . 5 0 2}$ & $\mathbf{9 1 4}$ & $\mathbf{5 . 5 8 8}$ & $\mathbf{1 4 , 0 6}$ & $\mathbf{8 5 , 9 4}$ \\
\hline
\end{tabular}

FONTE: IBGE, Censo Agropecuário (2006). 
por parte das comunidades locais, que, por vezes, se opõem fortemente às iniciativas propostas.

Em razão da grande quantidade de críticas que emergem diante dos grandes projetos de desenvolvimento, às vezes muito dispersas, optou-se por enfocar este estudo nas críticas a três grandes empreendimentos: a construção da base de apoio logístico offshore pela C-Port Brasil Logística Offshore Ltda., a construção do Itaoca Terminal Marítimo de Referência, pela Itaoca Offshore, e a construção do Porto Central, pela TPK Logística e Porto de Roterdã.

A base de apoio logístico da C-Port Brasil Logística Offshore Ltda. tem os objetivos de atender à crescente demanda de mercado; contribuir para o aumento da eficiência logística no estado do Espírito Santo, representando uma desconcentração logística e o atendimento portuário no estado; e ser um instrumento para alavancar plataformas exploratórias de petróleo nas bacias de Campos e do Espírito Santo (C-Port Brasil Logística Offshore Ltda., s.d.).

Localizada na praia da Gamboa, no distrito de Itaipava, no município de Itapemirim, essa base de apoio logístico ocupará uma área aproximada de 143 ha (sendo 118 offshore e 25 onshore) e contará com áreas de estágio, berços de atracação cobertos e descobertos, berços de atracação para inspeções e reparos navais, instalações de apoio operacional, subestação de energia, área para gerenciamento de resíduos, alojamentos, galpões para armazenagem, tanques de armazenamento e de mistura e estruturas de apoio. Em sua fase de instalação, promete oferecer 1.600 empregos diretos e, em sua fase de operação, serão 460 empregos diretos (C-Port Brasil Logística Offshore Ltda., s.d.).

No presente momento, a C-Port, que já possui licença de instalação, aguarda a conclusão da rodovia do Contorno de Itaipava (que ligará a ES-060 à
ES-487), obra de responsabilidade do governo do estado, sem a qual não poderá iniciar suas obras (C-Port Brasil Logística Offshore Ltda., s.d.).

O Itaoca Terminal Marítimo de Referência possui como objetivos atender à crescente demanda de apoio logístico às atividades offshore; participar ativamente de programas que venham colaborar com o desenvolvimento das comunidades locais, município e estado; ser referência no atendimento do apoio logístico das atividades offshore como uma empresa genuinamente capixaba; gerar retorno aos acionistas, aos parceiros, aos clientes e aos funcionários; e ampliar a formação de mão de obra local (Itaoca Offshore, s.d.).

Localizado na praia de Itaoca, no distrito de mesmo nome, no município de Itapemirim, esse empreendimento contará com as seguintes estruturas/serviços: berços para atracação, movimentação de cargas, disponibilidade de áreas administrativas, fornecimento de fluidos de perfuração, heliporto, armazenamento de cargas e materiais, coleta e destinação de resíduos, fornecimento de água, fornecimento de combustíveis. Em sua fase de instalação, promete oferecer 650 empregos diretos e, no pico de sua fase de execução (cerca de quatro anos após o início de suas atividades), cerca de 900 empregos diretos (Itaoca Offshore, s.d.).

Atualmente (primeiro semestre de 2016), o Itaoca Offshore já conta com a licença de instalação. Entretanto, devido à crise econômica internacional, aguarda momentos melhores para iniciar os investimentos, segundo entrevista realizada com um de seus diretores.

Já o Porto Central, o maior empreendimento dentre os três, é um "complexo industrial portuário privado multipropósito" desenvolvido no modelo de condomínio portuário. Sob o conceito de cluster, por meio do qual "terminais com atividades similares são estrategicamente agrupados para viabilizar 
sinergias e otimizar a eficiência operacional", o projeto apresenta sete setores principais: óleo e gás (incluindo GNL); minerais (como minério de ferro); produtos agrícolas (como soja, milho e fertilizantes); carga geral (produtos siderúrgicos, mármore e granito, carros e equipamentos); contêineres; indústrias offshore: base de apoio e estaleiros navais; e geração de energia (Porto Central, 2016).

Localizado no município de Presidente Kennedy, entre as praias de Marobá e das Neves, o Porto Central ocupará uma área de 2.000 ha e, por ser um porto de áreas profundas, abrirá um canal com 25 metros de profundidade que permitirá a atracação de navios de grandes calados (Porto Central, 2016).

Sua licença prévia foi emitida pelo Ibama em dezembro de 2014 e no presente momento estão sendo elaborados os documentos necessários para a liberação da licença de instalação. Em dezembro último, foi anunciada a previsão de início das obras em 2016. Vale destacar que a construção será em módulos, o que, se prevê, possibilitará o início de parte de suas operações em curto espaço de tempo (Porto Central, 2016).

Em razão do porte dos investimentos, é grande o número de parcelas da população afetadas por tais empreendimentos. A pesquisa de campo mostrou serem mais significativas as críticas empreendidas pelos pescadores artesanais, visto que é esse segmento social da comunidade local que será mais fortemente atingido por tais investimentos, principalmente em razão das áreas de exclusão da pesca marítima, da influência direta (ou indireta) nos pesqueiros da região, bem como na fauna marinha, e da proibição de circulação de pequenas embarcações, entre outras consequências.
Itaipava é um distrito do município de Itapemirim, localizado no litoral sul do Espírito Santo, distante cerca de $90 \mathrm{~km}$ da capital do estado, Vitória. Possui uma população de aproximadamente $11 \mathrm{mil}$ moradores e cerca de 2.800 pescadores que, em sua maioria, não são proprietários dos barcos, trabalhando em sistema de parceria. Nesse sistema, o dono do barco fica com $35 \%$ a $40 \%$ da renda obtida e o restante é dividido com a tripulação.

As artes de pesca mais utilizadas em Itaipava são a pesca de linha de fundo, o espinhel e o currico, atingindo uma profundidade de até 35 metros. Os petrechos ${ }^{6}$ utilizados são o espinhel com 500 a mil anzóis, para pesca de meca (Xiphias gladius), dourado (Coryphaena hippurus), atum (Thunnus spp.) e tubarão (Carcharhinus spp.), a pargueira com dez a 20 anzóis, para pesca de namorado (Pseudopercis numida), pargo (Pagrus pagrus) e garoupa (Epinephelus spp.), e a linha com isca viva, para a pesca de dourado (Coryphaena hippurus) e atum (Thunnus spp.). O tamanho médio das embarcações é de 12 metros, o que permite a navegação em grandes distâncias, até uma profundidade de 600 metros em mar aberto, e, dessa maneira, o exercício do que denominam de pesca multiespecífica. ${ }^{7}$

Dentre as principais críticas empreendidas, destacam-se a proibição da pesca no entorno das plataformas de petróleo, que, em razão da luminosidade e de dejetos orgânicos, atraem os cardumes; as atividades de dragagem e pesquisas sísmicas, que espantam os cardumes dos principais pontos pesqueiros; e a ausência de um píer para descarregar o pescado (e outros investimentos em infraestrutura, como câmaras frias, fábricas de gelo, unidades de processamento de pescado), entre outras. Espe-

\footnotetext{
6 Nome dados pelos pescadores aos instrumentos e à arte utilizados na pesca

Pesca de mais de uma espécie em cada saída para o mar.
} 
cificamente em relação à instalação da Base de Apoio Logístico da C-Port, na praia da Gamboa, as principais críticas dizem respeito à circulação de grandes embarcações e rebocadores na região, o que oferecerá risco aos pescadores. ${ }^{8} \mathrm{~A}$ crítica mais contundente, nessa e em outras localidades, é: "Eles querem acabar com a pesca”. Em alguns momentos, esse "eles" se refere aos empreendimentos e, em outros, ao poder público. O presidente da Colônia de Pesca Z-10 de Itaipava afirmou que o que está acontecendo é um "massacre" dos pescadores.

A comunidade de Pontal de Marataízes localiza-se entre a foz do rio Itapemirim, em sua margem esquerda, e a praia de Itaoca, no município de Marataízes, distante de Vitória cerca de $120 \mathrm{~km}$. Possui uma população de aproximadamente 1.400 habitantes, dos quais cerca de 600 são pescadores que trabalham em aproximadamente cem barcos (parte deles motorizada e com casarias, possuindo aproximadamente 9 metros, e outra parte são embarcações entre 3,5 metros e 5 metros, a remo, para a pesca de camarão até 500 metros da costa). Aqui o sistema também é de parceria, e a venda do pescado é feita por intermédio de atravessadores.

O Pontal é o maior produtor de camarão-rosa, camarão-sete-barbas (Farfantepenaeus paulensis e Xiphopenaeus kroyeri, respectivamente) e lagosta (Panulirus argus) do estado. Dentre os principais petrechos de pesca, encontram-se o covo para a captura da lagosta (Panulirus argus), a rede de espera para a pesca do cação (Carcharhinus spp.) e da corvina (Micropogonias spp.), a linha de mão para a pesca do peroá (Balistes spp.) e do pargo (Pagrus pagrus) e o espinhel para a pesca de sirioba (Lutjanus analis), anchova (Pomatomus saltatrix), badejo (Mycteroperca spp.) e garoupa (Epinephelus spp.) (Secretaria de Agricultura, Abastecimento, Aquicultura e Pesca, 2005).

A principal crítica realizada pela comunidade do Pontal (confirmada pela Colônia de Pesca de Marataízes, pela Associação de Pescadores do Pontal e pela Associação de Moradores do Pontal) diz respeito à área de exclusão da pesca do camarão. Com a instalação do terminal portuário de Itaoca, $100 \%$ dos camaroeiros serão proibidos de pescar. Mesmo não sendo proibidos de pescar, os demais pescadores (de lagosta, peroá, entre outros) também expressam sua preocupação com o aumento dos riscos de acidentes em razão da circulação, nessa área, de grandes embarcações. Eles afirmam que, embora existam regras de navegação, muitos rebocadores não as cumprem e acidentes estão ocorrendo. Outra crítica, repetida por vários pescadores, é a de que a circulação de grandes embarcações também poderá afastar os cardumes.

A comunidade de Marobá localiza-se na divisa entre Marataízes e Presidente Kennedy e pertence a este último município. Com uma população de aproximadamente 520 pessoas, possui cerca de 60 pescadores cadastrados nas colônias de Marataízes e de Presidente Kennedy e apenas seis pequenas embarcações a vela de 3,5 metros registradas. Vale destacar que, em razão da ausência de local para desembarque de pescado e nenhuma infraestrutura de pesca nessa localidade, há pescadores que trabalham em embarcações registradas em Cabo Frio (RJ), Macaé (RJ) e Marataízes (ES).

As principais espécies capturadas por pescadores locais são a pescadinha (Macrodon ancylodon), capturada com rede de espera, a peroá (Balis-

\footnotetext{
8 Um exemplo foi o acidente, ocorrido em outubro de 2015, entre um barco de pesca artesanal e um rebocador, no qual, dentre quatro tripulantes, apenas um sobreviveu (disponível em: <http:/g1.globo.com/espirito-santo/noticia/2015/10/pescador-morre-e-dois-desaparecem-em-acidente-com-barco-no-es.html>. Acesso em: 9 abr 2016).
} 
tes spp.), a corvina (Micropogonias spp.), o cação (Carcharhinus spp.), a arraia (Atlantoraja spp.), o baiacu (Lagocephalus laevigatus) e o pargo (Pagrus pagrus), capturados com a pargueira. No verão, o volume pescado varia de $200 \mathrm{~kg}$ /dia a $300 \mathrm{~kg} / \mathrm{dia}$, sendo essa estação a de maior safra da pesca na comunidade de Marobá.

Em Marobá existe uma cooperativa de aquicultura chamada Batalha, que objetiva "o desenvolvimento de projetos socioambientais na comunidade e o estabelecimento da população em seus locais de origem", realizando trabalhos que não destoam de suas práticas comuns, como a confecção de redes e estruturas para cultivo de moluscos e peixes (Secretaria de Agricultura, Abastecimento, Aquicultura e Pesca, 2005).

Dentre as principais criticas dessa comunidade, além daquelas que já foram mencionadas, sintetizadas nas expressões "eles querem acabar com a pesca", "para eles os pescadores não existem", a exclusão das áreas de pesca, entre outras, uma que chama a atenção diz respeito ao questionamento da maneira como são investidas as indenizações dos planos de compensação da atividade pesqueira por parte dos empreendedores. Segundo alguns entrevistados, esses investimentos não vão para a pesca, mas se transformam em compras de terrenos, investimentos em comunidades quilombolas que não são pescadoras, na construção de quadra de esportes, entre outros.

Na pesquisa de campo, foi possível perceber que a motivação dos agentes sociais que se opõem aos grandes projetos de desenvolvimento está fortemente embasada em um sentimento de injustiça que causa indignação e mobiliza críticas. Percebe-se também que as concepções de justiça/injustiça dos diferentes grupos em conflito se apoiam em cosmologias distintas. Por exemplo, diferentemente das críticas realizadas pelos pescadores, para as empresas, é justo que possam realizar seus investimentos nas áreas escolhidas uma vez que obtêm as licenças e atendem às condicionantes que a legislação exige. É justo também que possam obter retorno de seus investimentos financeiros, até porque estariam contribuindo para o desenvolvimento, gerando emprego e renda para a população e pagando impostos.

Na sua visão de mundo, as empresas estariam promovendo a melhoria na vida das pessoas. Nessa perspectiva, se os pescadores ficarem impedidos de pescar, isso não se apresentaria como um problema porque "a pesca não geraria muitos lucros mesmo" e tampouco permite que o pescador tenha uma vida com acesso ao consumo dos bens que proporcionam conforto a eles e suas famílias.

\section{Críticas e cosmologias no conflito ambiental: uma abordagem teórica}

No Brasil, os estudos sobre a "questão ambiental" se caracterizam pela grande presença de pesquisas sobre conflitualidades no interior da relação sociedade-natureza. ${ }^{9}$ Em alguns dos cenários empíricos das pesquisas se percebe que há algo a mais que a disputa por "recursos" materiais e simbólicos dos territórios. Alguns autores brasileiros que estudam essa temática (ver abaixo) partilham da ideia de que os conflitos como "dimensão" ambiental são meros conflitos sociais em torno dos quais se disputam o ambiente e/ou a utilização/ distribuição de "recursos do território". 
Resumidamente, a título de ilustração, se podem destacar ao menos três abordagens que integram grupos de pesquisadores e trabalhos que debatem, sob diversos enfoques teórico-epistemológicos, como a sociologia pode incorporar as análises sobre o ambiente: Fleury (2013), Almeida \& Premebida (2014) e Fleury et al. (2014). O primeiro grupo é composto de autores brasileiros que dialogam com a sociologia ambiental em nível internacional, orientando suas pesquisas nos debates sobre arenas públicas, sociedade de risco, modernização ecológica, sustentabilidade e interdisciplinaridade, como, por exemplo, Fuks (1998), Ferreira (1996) e Guivant (1998).

Um segundo grupo, bem significativo no Brasil, é formado por pesquisadores que apoiam seu arcabouço teórico-reflexivo na sociologia crítica de Pierre Bourdieu, discutindo conflitos ambientais a partir de relações simbólicas e de poder/dominação, como, por exemplo, Leite Lopes (2004), Acselrad (2005) e Zhouri (2010).

Já um terceiro bloco é constituído por autores mais identificados com a área da antropologia, discutindo conflitos ambientais a partir de análises sobre povos tradicionais e grandes projetos de desenvolvimento, entre eles Almeida (1996), Carneiro da Cunha (2009), Magalhães (2007) e Ribeiro (1991).

O tema da conflitualidade na relação sociedade-natureza no Brasil, embora se constitua em um campo ainda em construção, vem assumindo relevância que pode ser verificada não apenas pela contribuição dos pesquisadores mencionados, mas também pela existência de diversos grupos de trabalho voltados à sua discussão nos principais encontros brasileiros de ciências sociais. Destacam-se os encontros da Associação Nacional de Pesquisa e Pós-graduação em Ciências Sociais (Anpocs), da Associação Nacional de Pesquisa e Pós-graduação em Ambiente e Sociedade (Anppas) e no Congresso Brasileiro de Sociologia (CBS), entre outros.

Outra perspectiva analítica, diferente das três acima brevemente sistematizadas, vem sendo desenvolvida pelo Grupo de Pesquisa em Tecnologia, Meio Ambiente e Sociedade (Temas/UFRGS). Ela propõe o conceito de conflito ambiental interpretando-o como categoria híbrida de sociedade e natureza, com o objetivo de reforçar sua carga cosmopolítica: "Os conflitos são parte crucial do encontro de perspectivas e estão no centro das relações sociais, isto é, o mundo é um espaço de conflitos que depende de agenciamentos e do encontro entre pontos de vista" (Fleury, 2013, p. 298). Tais conflitos, portanto, emergiriam no contraponto entre diferentes cosmovisões, por intermédio de diferentes sentimentos de justiça/injustiça que estão na base da crítica, considerando-se a crítica como formas (contestadoras) enraizadas no contexto social, no qual os agentes são capazes de organizar seus interesses.

Dessa maneira, ao se considerar um agenciamento recíproco (Maia, 2015) entre elementos de sociedade e de natureza na construção de cosmologias, parte-se da hipótese de que os sentimentos de justiça/injustiça que motivam os conflitos ambientais não se expressam em termos de totalidades sociais dadas. Ao contrário, as razões que mobilizam os diferentes agentes sociais em situações de conflitos ambientais são construídas a partir da (e na) relação sociedade-natureza.

Uma das propostas que mais se aproximam da possibilidade de romper com a primazia do social nos estudos sobre a questão ambiental veio dos Estudos Sociais da Ciência e Tecnologia (ESCT). Estes, ao enfocarem as análises acerca da produção do conhecimento científico e a elaboração e implantação de tecnologias, deparam, necessariamente, com a interface social-natural e, ao procurarem 
conceitos que possam distinguir os ordenamentos da natureza pela ciência e da sociedade pela cultura, desenvolvem uma linguagem comum para os híbridos (Bloor, 1982; Latour, 1994).

A proposta de Latour (1995) é romper com a clara separação entre sociedade e natureza presente na moral utilitarista kantiana, que está baseada na relação entre meios e fins, e considerar a hipótese da constituição de uma moral construída a partir da coprodução sociedade-natureza. Para tanto, se faz necessário levar em consideração as proposições de Latour acerca da sociedade ocidental moderna. Para ele, a modernidade instaurou uma Constituição que define e separa os humanos e não humanos, suas propriedades e suas relações. A divisão sociedade-natureza é, portanto, uma criação humana. Há, porém, uma série de "situações estranhas que a cultura intelectual não sabe bem classificar" (Latour, 1995, p. 9), pois estão permeadas tanto por objetos sociais como por objetos naturais.

A partir dessa constatação, Latour parte da noção de redes sociotécnicas, reconhecendo agência a humanos e não humanos que se tornam mediadores dessas redes, para propor um modelo de análise em que os actantes (agentes-rede) constituem híbridos que não existem em si; ao contrário, são fluxos que devem ser traduzidos por intermédio de um agenciamento recíproco entre os polos sociedade e natureza.

Francis Chateauraynaud e colaboradores desenvolveram a proposição de tomar o ambiente como parte integrante de redes sociotécnicas que emergem e se estabilizam por meio de processos de definição e de resolução de situações problemáticas (Chateauraynaud \& Torny, 2005). Assim, o ambiente é definido por eles como híbrido de sociedade e natureza, ou fluxos a serem traduzidos.

Para o desenvolvimento da pesquisa em tela, são abordadas duas categorias analíticas a partir dessa perspectiva de coprodução de sociedade e de natureza, quais sejam, ambiente e justiça/injustiça. Entende-se que, de acordo com a maneira como se constrói cada uma dessas categorias, elas podem vir a ter um caráter "natural" ou "social". Assim, ambiente e justiça/injustiça são tratados como fluxos coconstruídos de sociedade e natureza.

Tem-se como pressuposto que, também na definição das concepções de justiça/injustiça, que mobilizam conflitos ambientais, o social e o natural não se separam e se expressam conforme uma política pluriversa (De la Cadena, 2010), na qual diferentes mundos com suas formações socionaturais e suas visões conflitantes devem ser considerados.

Nesse sentido, retomando a crítica à proposição kantiana utilitarista e ampliando e fortalecendo a categoria de conflitos ambientais, é importante o que propõe Stengers (2007) para a noção de "cosmos". Baseada na crença do "bem comum", a noção kantiana de "cosmos" relaciona-se à tentativa de construir um único modo bom para se viver. Nessa perspectiva, todas as controvérsias, ameaças ou espaços de hesitação se tornariam "questões planetárias" nas quais a ideia de "bem comum" se universaliza e se despolitiza. Conforme a autora, o "cosmos" não designa mundos ou tradições particulares e tampouco pode ser designado por um projeto que visa englobar tudo:

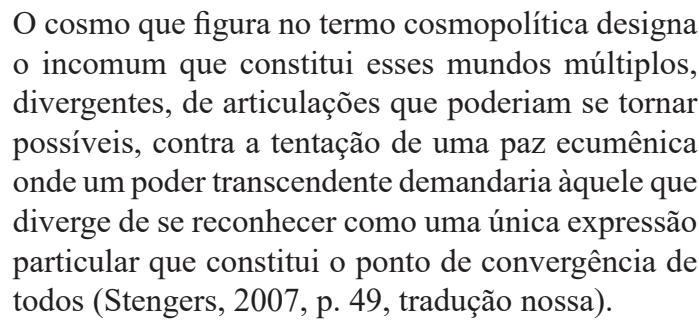

A autora reforça que a dimensão cosmopolítica requer que as questões se coloquem de maneira coletiva: 
Ao termo "cosmopolítica" corresponde aquilo que não é nem uma atividade, nem uma negociação, nem uma prática, mas o modo pelo qual se atualiza a copresença problemática de práticas: a experiência, sempre no presente, daquele em que atravessa o sonho do outro. Entrecaptura não simétrica que não garante nada, não autoriza a nada e não pode ser estabilizada por nenhuma restrição, mas por onde aquele que atravessa e aquele que é atravessado se submetem um ao outro ao exame que constitui a efração desse terceiro termo "assustador", não apropriável por nenhuma medida: "Nós não estamos sozinhos no mundo". (Stengers, 2003, p. 355, tradução e grifos nossos).

É exatamente a "copresença problemática de práticas" ou os momentos de "entrecapturas não simétricas" que se pretende colocar em evidência com a finalidade de destacar as assimetrias existentes entre as comunidades locais e os grupos que dirigem os grandes empreendimentos que visam "ao desenvolvimento" no litoral sul do Espírito Santo. Mais do que isso, pretende-se demonstrar que os sentimentos de justiça/injustiça também são construídos "em presença", constituindo-se em uma proposição cosmopolítica.

Boltanski (1990) propõe um deslocamento da crítica, que antes era vista como tarefa apenas dos sociólogos, para a crítica dos agentes sociais, no interior da ordem social. Para ele, os agentes sociais dispõem de capacidades críticas que não se limitam àquelas realizadas pelas instituições formais (como partidos, governos, movimentos sociais etc.), mas ocorrem no cotidiano das pessoas que, de diversas maneiras, manifestam indignações baseadas em sentimentos de injustiça:

[...] a crítica põe em cena um mundo no qual a exigência de justiça é transgredida ininterruptamente. Ela revela a hipocrisia das pretensões morais que dissimulam a realidade das relações de forças, da exploração e da dominação (Boltanski \& Chiapello, 2009, p. 62).
Para esses autores, os conflitos ocorrem quando os agentes sociais se engajam em criticas colocando em questão seus sentidos de justiça, justificam suas ações e buscam convergir para um acordo. Tanto as críticas como os acordos são baseados nos sentimentos de justiça/injustiça da situação em questão. A luta por justiça, para Boltanski (1990), é sempre uma luta por uma ordem de grandeza que supõe um acordo sobre um princípio de equivalência que estabelece uma grandeza relativa entre os seres em presença. A escolha que o autor faz pela categoria de ordem de grandeza na definição de sua concepção de justiça, e não a de valor, comumente utilizada pela sociologia da ação, se refere ao fato de que os valores nem sempre estão relacionados à busca por justiça e, além disso, a ordem de grandeza permite colocar em relação, num agenciamento justo e justificável, diferentes coisas e pessoas.

Nessa perspectiva, um segundo aspecto a ser considerado é que, para Boltanski (1990), a ordem de grandeza se relaciona aos arranjos particulares capazes de suscitar acordos generalizáveis. Assim, esse termo está relacionado a um princípio de equivalência geral que funda acordos negociáveis e mais ou menos aceitáveis pelos grupos em conflito. Essa ordem de grandeza não está fixada no grupo ou nas pessoas, como um determinante culturalista. Ao contrário, ela pode se apresentar de maneira diferente conforme a situação e os agentes em presença.

O quadro teórico aqui brevemente apresentado pode sugerir questionamentos como: os sentimentos de justiça/injustiça que mobilizam a crítica social, considerando-se seu caráter pragmático, não estariam relacionados às diferentes cosmovisões, ou à copresença problemática de práticas? Coloca-se em questão a noção de justiça como um sentimento comumente partilhado por toda a sociedade, que está na base da constituição de uma ordem 
de grandeza (ou cité), e sugere-se, ao contrário, a existência, no caso dos conflitos ambientais, de uma diversidade de concepções de justiça, o que aqui se propõe denominar (ao menos provisoriamente) de "cosmojustiça".

\section{Combinando a pesquisa de campo e o quadro teórico proposto: reflexões iniciais}

As reflexões a seguir são consequência de observações de campo, de entrevistas em profundidade e de informações de empresas e de órgãos dos governos estadual e federal obtidas em análise de materiais de divulgação, notícias de jornais, entre outros. Essas reflexões são moduladas, em um exercício também inicial, pelo quadro teórico que brevemente se anuncia na seção anterior.

Diante dos grandes projetos portuários em questão, o primeiro elemento que se destaca é que as comunidades de pescadores artesanais, ao verem reduzidas suas áreas de pesca e a quantidade de pescado, passam a ter sua sobrevivência questionada, o que implica reações de defesa de seus modos de vida. Para o presidente da Associação de Pescadores de Ubu e Paraty, a atividade pesqueira, bem como a comunidade de pescadores, está com sua "sobrevivência ameaçada":

Mais e mais empresas, mais e mais destruição ambiental vai acontecendo. No entanto, nós não podemos nos calar diante de tanta destruição. Temos que fazer alguma coisa. Por exemplo, formar grupos de pessoas combativas, que não se curvem diante do capital e sejam criativos na ampliação das possibilidades de melhoria da situação econômica, que sejam capazes de lutar para frear, com todas as forças, os invasores que destroem a natureza; ela [a natureza] chora e grita por socorro! Vamos socorrê-la. Precisamos de algo mais, para viver muito mais e deixar os recursos naturais preservados para as futuras gerações (Branco, 2010, p. 148 apud Ramos et al. 2009).

Por outro lado, os agentes governamentais e as empresas privadas envolvidas advogam a necessidade de maior produção de energia (fundamentalmente, o petróleo extraído da camada pré-sal) para a promoção do desenvolvimento do estado do Espírito Santo, do Brasil e da infraestrutura logística que permitirá ampliar as exportações. Os "recursos naturais" aqui são vistos como fontes de energia necessárias ao crescimento industrial e econômico do país, bem como fonte de obtenção de dividendos para as empresas. Governo estadual e empresários privados têm uma concepção de desenvolvimento baseada na industrialização e na urbanização, pouco considerando as dinâmicas produzidas pelas atividades produtivas das comunidades locais, como a pesca artesanal, por exemplo.

Já nas primeiras incursões ao campo se pôde perceber, por intermédio das conversas com os pescadores, a forte presença da ideia de justiça: "É justo que apenas as grandes empresas possam 'utilizar' o mar?"; “é justo que não se possa mais pescar para que as grandes embarcações possam transitar livremente pelo oceano?"; "é justo ter que sair se eles [as grandes empresas] chegaram depois? Se nós estamos aqui há muito tempo?”. Esses são alguns dos questionamentos que sugerem haver, na presente situação de conflito, diferentes concepções de justiça que mobilizam os agentes a promover a crítica social.

Diante do governo e dos empresários, para os quais os grandes projetos em questão são justificados pela necessidade de desenvolver uma região "atrasada", "pouco desenvolvida", promovendo a industrialização/urbanização dos municípios, os pescadores se apresentam como o Idiota de Gilles 
Deleuze. ${ }^{10}$ Para eles, o que há de mais importante no desenvolvimento é a manutenção de seu modo de vida, de suas expressões culturais e de seu modo de sobrevivência, a pesca. Nesse contexto, a pesca é para o pescador algo mais do que um trabalho realizado para o sustento da família, do qual não se pode abrir mão para exercer qualquer outra atividade. "A pesca é uma cultura", afirmou uma pescadora em entrevista. Ela envolve um conjunto de conhecimentos, de crenças, uma relação específica com o mar, o sol, a lua, as marés, os ventos, os santos, a organização das famílias, das comunidades, do trabalho das mulheres (que influencia o processamento do pescado, o artesanato feito de conchas, entre outros). Assim, o sentimento de injustiça subjacente às críticas aos grandes projetos se relaciona a um amplo conjunto de fatores que não pode ser resolvido com indenizações ou programas de renda, como supõem os agentes das empresas ou do governo.

Dessa maneira, a copresença problemática de práticas dos empresários e seus representantes, por um lado, e dos pescadores artesanais, por outro, constitui-se em conflito ambiental motivado por concepções de justiça/injustiça distintas. Se para os agentes das empresas é justo que se possa utilizar o território (considerados aqui o mar e parte do continente) para expandir seus negócios, aumentar sua fonte de lucros, promover o desenvolvimento, gerar empregos, entre outros, para os pescadores, o que é justo é poder continuar pescando como sempre fizeram seus antepassados, morando na comunidade onde nasceram, ensinando seu ofício aos seus descendentes. Parece haver uma racionalidade diferente que envolve a noção de justiça/injustiça de agentes de empresas e pescadores. Do ponto de vista da pesquisa em tela, essas diferenças resultam das diferentes cosmovisões desses agentes.

As entrevistas e a observação realizadas na pesquisa de campo demonstram que a visão de mundo dos agentes das empresas, no que tange ao desenvolvimento, relaciona-se à noção de crescimento econômico, que necessita de uma produção cada vez maior de energia, que demanda investimentos em logística e que gera emprego e renda melhorando a vida de todos. Sua relação com o ambiente se dá de maneira "desterritorializada", no sentido de que qualquer lugar que ofereça as mesmas condições pode ser alvo desses investimentos, não importando as características naturais e culturais ou quais comunidades vivem ali. Quando questionados sobre a razão da escolha daquele local para o investimento, os agentes das empresas respondem apenas que isso é devido a "características técnicas".

No que tange à concepção de justiça para os agentes das empresas, pode-se afirmar que esta fica restrita ao cumprimento da legislação vigente e ao pagamento das "condicionantes ambientais". O que importa para eles é a modernização, a industrialização, a utilização de novas tecnologias, a inovação e a crença de que, se as empresas promoverem isso, promoverão o bem comum, porque todos supostamente serão beneficiados.

Ainda para os agentes das empresas, a presença de pesadores artesanais figura como a manutenção do atraso, do arcaico, do rudimentar. Nas manifestações abertas ou de forma sub-reptícia, verifica-se que os pescadores são vistos como pessoas ignorantes que não são capazes de com-

\footnotetext{
10 Stenger (2007) retoma um personagem conceitual de Gilles Deleuze, o "Idiota", para demonstrar a concepção de "cosmos" que, de seu ponto de vista, está relacionada aos espaços de hesitação, aos interstícios. O idiota é aquele que sempre retarda as pessoas, que resiste à maneira como a situação se lhe apresenta, porque para ele parece haver "algo mais importante" a ser pensado ou discutido.
} 
preender que o grande projeto a ser instalado será bem melhor para o desenvolvimento da região e do Brasil e, nesse caso, justo seria que os pescadores fizessem cursos para se qualificar e se transformar em empregados, nessas ou em outras empresas. Outros elementos simbólicos são mobilizados para justificar esse discurso, como, por exemplo, a garantia de renda/salário todo mês, a carteira assinada, férias, $13^{\circ}$ salário, possibilidades de adquirir bens de consumo, entre outros.

Ao contrário, a cosmovisão dos pescadores artesanais está baseada na ideia de que o desenvolvimento enfraquece e por vezes impede a continuidade de sua atividade como pescadores. Sua relação com o ambiente não se resume à exploração dos "recursos naturais", como a captura do pescado; amplia-se para uma visão de território onde importam sua história, a presença da natureza (a restinga, o mangue), a relação com as comunidades locais e a identidade como pescador.

A concepção de justiça dos pescadores artesanais vai além do cumprimento das leis vigentes, abrangendo, inclusive, um questionamento a essas mesmas leis, no que diz respeito tanto à legislação que ampara a instalação dos grandes empreendimentos como àquela que regula sua própria atividade.

Quando acusados de arcaicos e rudimentares, que deveriam deixar a pesca para ter outra profissão, que deveriam estudar, eles rebatem dizendo que o conhecimento da pesca, transmitido oralmente há gerações, apenas eles têm. Um pescador entrevistado chegou a afirmar que professores de engenharia de pesca vão até eles para aprender sobre seu ofício para depois elaborarem as "apostilas" para suas aulas. Eles afirmam que já têm uma profissão e não acham justo que sejam forçados a mudar para serem empregados, terem que cumprir horários de trabalho definidos pelos patrões, perderem sua liberdade de ir e vir para ficarem restritos ao ambiente de trabalho de uma empresa.

Acredita-se, assim, que é possível pensar em um conjunto de justificativas que são mobilizadas por diferentes sentimentos de justiça/injustiça e ações em que o ambiente (produto do amálgama de sociedade e natureza) assume papel central. Entretanto, no que tange ao conflito ambiental, talvez não seja possível a construção de um único mundo bom para viver, como sugere a proposição kantiana de justiça como bem comum.

Sendo assim, concorda-se com Boltanski (2009) no que diz respeito ao fato de que a crítica se enraíza na ordem social e parte de sentimentos de injustiça, mas discorda-se no que diz respeito à possibilidade de construção de uma nova ordem de grandeza (ou cite) em que o ambiente se constitua em elemento central capaz de unificar tais sentimentos e dirimir conflitos. Isso porque parece claro que os sentimentos de injustiça que mobilizam a crítica, no conflito em tela, constituem-se em fluxo coconstruído de sociedade e natureza que representam uma diversidade de mundos.

\section{Considerações finais}

Ao se considerar o conflito ambiental que se instala a partir das críticas aos grandes projetos de desenvolvimento do ponto de vista de sua carga cosmopolítica, verifica-se a irredutibilidade ao "bem comum" ou a uma única ordem social.

No decorrer desse esforço de pesquisa até aqui, objetiva-se ainda questionar a noção de justiça como "redistribuição", ou como justiça redistributiva, para verificar se há, do ponto de vista das questões ambientais, a possibilidade da realização de uma "justiça ambiental", conforme sugere Alier (2007). 
Do ponto de vista do debate acerca do discurso do desenvolvimento e suas críticas, pretende-se ainda colocar em questão se, partindo das premissas teóricas aqui expressas, é possível pensar em desenvolvimento (no singular) como algo capaz de promover a melhoria de vida de todos em geral. Do

\section{Referências}

Abe, A. T. Anchieta/ES: avaliação do Plano Diretor Municipal. Anchieta - ES: Prefeitura Municipal, s/d.

Acselrad, H. Conflitos ambientais no Brasil. Rio de Janeiro: Relume-Dumará, 2005.

Alier, J. M. O ecologismo dos pobres: conflitos ambientais e linguagens de valoração. São Paulo: Contexto, 2007.

Almeida, A. W. B. de. Refugiados do desenvolvimento: os deslocamentos compulsórios de índios e camponeses e a ideologia da modernização. Travessia, 30-35, 1996.

Almeida, J.; Premebida, A. Histórico, relevância e explorações ontológicas da questão ambiental. Sociologias, 16(35), 14-33, 2014.

Bloor, D. Durkheim and Mauss revisited: Classification and the sociology of knowledge. Studies in History and Philosophy of Science, 13(4), 267-297, 1982.

Boltanski, L. L'Amour et la Justice comme compétences. Paris: Éditions Métailié, 1990.

Boltanski, L. De la critique: Précis de sociologie de l'émancipation. Paris: Gallimard, 2009.

Boltanski, L.; Chiapello, È. O novo espírito do capitalismo. São Paulo: Martins Fontes, 2009.

Branco, M. Pescadores artesanais do Espirito Santo. Curitiba: Esplendor, 2010.

Chateauraynaud, F.; Torny, D. Mobiliser autour d'un risque. Des lanceurs aux porteurs d'alerte. In: Lahellec, C. (Ed.). Risques et crises alimentaires. Paris: Lavoisier/Tec\&Doc, 2005. p. 329-339. ponto de vista da pragmática, e partindo das diversas cosmovisões, será possível reduzir as diferentes visões do que seja desenvolvimento em uma única proposta de ação que pretenda unificar todas?

Essas são questões que se pretende ainda debater no exercício do presente esforço de pesquisa.

C-Port Logística Offshore Brasil Ltda. Relatório de impacto ambiental da Base de Apoio Logístico Offshore. Itapemirim-ES, s/d.

Cunha, M. C. da. Cultura com aspas e outros ensaios. São Paulo: Cosac Naify, 2009.

De La Cadena, M. Indigenous Cosmopolitics in the Andes: Conceptual Reflections beyond "Politics". Cultural Anthropology, 25(2), 334-370, 2010.

Ferreira, L. da C.; Viola, E. Incertezas de sustentabilidade na globalização. Campinas: Editora da UNICAMP, 1996.

Fleury, L. C. Conflito ambiental e cosmopolíticas na Amazônia brasileira: a construção da Usina Hidrelétrica Belo Monte em perspectiva. Tese (Doutorado em Sociologia) - UFRGS, 2013.

Fleury, L. C.; Almeida, J.; Premebida, A. O ambiente como questão sociológica: conflitos ambientais em perspectiva. Sociologias, 16(35), 34-82, 2014.

Fuks, M. Arenas de ação e debate públicos: conflitos ambientais e a emergência do meio ambiente enquanto problema social no Rio de Janeiro. Dados, 41(1), 1998. doi: 10.1590/S0011-52581998000100003

Guivant, J. S. Conflitos e negociações nas políticas de controle ambiental: o caso da suinocultura em Santa Catarina. Ambiente e Sociedade, 2, 101-123, 1998.

Itaoca Offshore. Relatório de impacto ambiental do Itaoca terminal marítimo. Itapemirim-ES, s/d.

Latour, B. Jamais fomos modernos. Rio de Janeiro: Ed. 34, 1994. 
Latour, B. Moderniser ou écologiser? A la recherche de la septième cité. Ecologie Politique, 13, 5-27, 1995.

Lopes, J. S. L.; Antonaz, D.; Prado, R.; Silva, G. A ambientalização dos conflitos sociais: participação e controle público da poluição industrial. Rio de Janeiro: Relume-Dumará, 2004.

Magalhães, S. Lamento e dor: uma análise sócio-antropológica do deslocamento compulsório provocado pela construção de barragens. Tese (Doutorado em Ciências Sociais) - UFPA, 2007.

Maia, C. A. Os impasses conceituais de Latour: o humano, o social e a simetria. In: Premebida, A.; Neves, Fabrício M.; Duarte, T. R. (Orgs.). Investigações contemporâneas em estudos sociais da ciência e tecnologia. Jundiaí, Paco Editorial, 2015. p. 87-118.

Martins, L. R. A agricultura familiar de Anchieta/ES sob a hegemonia do grande capital. Dissertação (Mestrado em Ciências Sociais em Desenvolvimento, Agricultura e Sociedade) - UFRRJ, 2014.

Porto Central. Web Page do Porto Central. 2016. Disponível em: $<$ http://www.portocentral.com.br/pb/>.

Ramos, M. H. R; Silva, A. I. da; Taide, S. G. de. Desenvolvimento local, saúde e meio ambiente: o impacto dos grandes projetos em Anchieta/ES, na região metropolitana da Grande Vitória, e em Macaé/RJ. Vitória: EMESCAM, 2009.
Ribeiro, G. Empresas transnacionais: um grande projeto por dentro. Rio de Janeiro/São Paulo: ANPOCS/ Marco Zero, 1991.

Secretaria de Agricultura, Abastecimento, Aquicultura e Pesca do Estado do Espírito Santo. Relatório do macro diagnóstico da pesca marítima do Estado do Espírito Santo. Vitória - ES: s/d.

Secretaria de Estado de Economia e Planejamento do Espírito Santo. Espírito Santo 2025: Plano de Desenvolvimento. Vitória - ES: Governo do Espirito Santo, 2006.

Secretaria de Estado Desenvolvimento. Web page do Governo do Espírito Santo. Disponível em: <http://www.es.gov. $\mathrm{br} /$ Governo/Secretarias/33/sedes--secretaria-de-estado-de-desenvolvimento.htm>. 2016. Acesso em: 03/05/2016.

Stengers, I. Cosmopolitiques I. Paris: La Découvert, 2003.

Stengers, I. La proposition cosmopolitique. In: Lolive, J.; Soubeyran, O. (Eds.). L'émergence des cosmopolitiques. Paris: Éditions La Découvert, 2007.

Zhouri, A.; Laschefski, K. Desenvolvimento e conflitos ambientais: um novo campo de investigação. In: Zhouri, A.; Laschefski, K. (Orgs.). Desenvolvimento e conflitos ambientais. Belo Horizonte - MG: Editora UFMG, 2010. p. 11-31. 